\title{
Current Long-Term Pharmacotherapies for the Management of Obesity
}

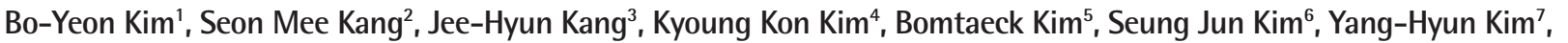
Jung-Hwan Kim ${ }^{8}$, Jae Hyun Kim ${ }^{9}$, Ga Eun Nam ${ }^{7}$, Ji Yeon Park ${ }^{10}$, Jang Won Son ${ }^{11}$, Hye-Jung Shin ${ }^{12}$, Tae Jung Oh ${ }^{13}$, Hyug Lee ${ }^{14}$, Eon-Ju Jeon ${ }^{15}$, Sochung Chung ${ }^{16}$, Yong Hee Hong ${ }^{17}$, Chong Hwa Kim ${ }^{18 * *}$, Committee of Clinical Practice Guidelines, Korean Society for the Study of Obesity (KSSO)

${ }^{1}$ Division of Endocrinology and Metabolism, Department of Internal Medicine, Soonchunhyang University Bucheon Hospital, Soonchunhyang University College of Medicine, Bucheon; ${ }^{2}$ Division of Endocrinology and Metabolism, Department of Internal Medicine, Sun Medical Center, Daejeon; ${ }^{3}$ Department of Family Medicine, Konyang University Hospital, Konyang University College of Medicine, Daejeon; ${ }^{4}$ Department of Family Medicine, Gil Medical Center, Gachon University College of Medicine, Incheon; ${ }^{5}$ Department of Family Practice and Community Health, Ajou University Medical Center, Suwon; ${ }^{6}$ Department of Psychiatry, Konyang University Hospital, Konyang University College of Medicine, Daejeon; ${ }^{7}$ Department of Family Medicine, Korea University College of Medicine, Seoul; ${ }^{8}$ Department of Family Medicine, Eulji Hospital, Eulji University School of Medicine, Seoul; ${ }^{9}$ Department of Pediatrics, Seoul National University Bundang Hospital, Seoul National University College of Medicine, Seongnam; ${ }^{10}$ Department of Surgery, School of Medicine, Kyungpook National University, Kyungpook National University Chilgok Hospital, Daegu; "Division of Endocrinology and Metabolism, Department of Internal Medicine, Bucheon St. Mary's Hospital, College of Medicine, The Catholic University of Korea, Bucheon; 12Department of Pediatrics, National Medical Center, Seoul; ${ }^{13}$ Department of Internal Medicine, Seoul National University Bundang Hospital, Seoul National University College of Medicine, Seongnam; ${ }^{14}$ Central St' Mary's Clinic Internal Medicine, Seoul; ${ }^{15}$ Division of Endocrinology and Metabolism, Department of Internal Medicine, Catholic University of Daegu School of Medicine, Daegu; ${ }^{16}$ Department of Pediatrics, Konkuk University Medical Center, Konkuk University School of Medicine, Seoul, ${ }^{17}$ Department of Pediatrics, Soonchunhyang University Bucheon Hospital, Soonchunhyang University College of Medicine, Bucheon; ${ }^{18}$ Division of Endocrinology and Metabolism, Department of Internal Medicine, Sejong General Hospital, Bucheon, Korea
\end{abstract}

Obesity is a serious and growing worldwide health challenge associated with type 2 diabetes mellitus, cardiovascular disease, osteoarthritis, some cancers, sleep apnea, asthma, and nonalcoholic fatty liver. The Korean Society for the Study of Obesity recommends that pharmacotherapy should be considered when intensive lifestyle modifications fail to achieve a weight reduction in obese patients with a body mass index $\geq 25 \mathrm{~kg} / \mathrm{m}^{2}$. Long-term medications for obesity have traditionally fallen into two major categories: centrally acting anorexiant medications and peripherally acting medications, such as orlistat. In this paper, we provide an overview of the anti-obesity medications currently available for the long-term and individualized treatment of obesity.

Key words: Obesity, Orlistat, Lorcaserin, Liraglutide, Naltrexone/bupropion extended-release, Phentermine/ topiramate extended-release

\author{
Received January 15, 2020 \\ Reviewed February 27, 2020 \\ Accepted March 23, 2020 \\ ${ }^{*}$ Corresponding author \\ Chong Hwa Kim \\ (iD) \\ https://orcid.org/0000-0002-4563-7772 \\ Division of Endocrinology and \\ Metabolism, Department of Internal \\ Medicine, Sejong General Hospital, \\ 28 Hohyeon-ro 489beon-gil, Sosa-gu, \\ Bucheon 14754, Korea \\ Tel: +82-32-340-1116 \\ Fax: +82-32-340-1236 \\ E-mail:drangelkr@hanmail.net
}

\section{INTRODUCTION}

Obesity is a serious and growing worldwide health challenge associated with type 2 diabetes mellitus (T2DM), cardiovascular disease, osteoarthritis, certain types of cancers, sleep apnea, asthma, and nonalcoholic fatty liver. The primary goals of obesity treatment are to improve obesity-related comorbid conditions and reduce the risk of developing future comorbidities. Lifestyle modification is fundamental for weight loss, but only results in limited weight loss and most patients regain at least some of the weight lost after 12

Copyright (C) 2020 Korean Society for the Study of Obesity

() This is an Open Access article distributed under the terms of the Creative Commons Attribution Non-Commercial License (https://creativecommons.org/licenses/by-nc/4.0/) which permits unrestricted non-commercial use, distribution, and reproduction in any medium, provided the original work is properly cited. 


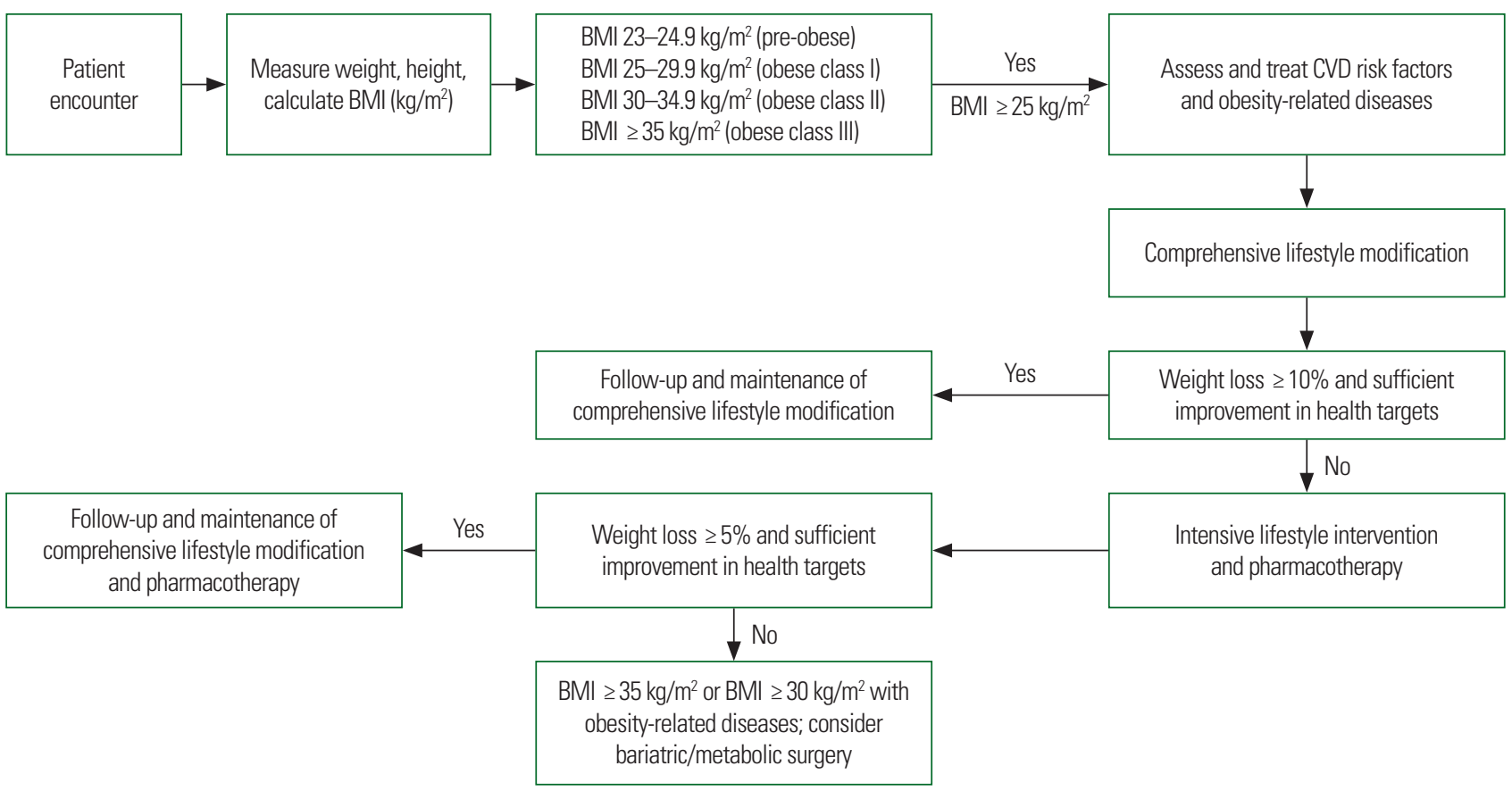

Figure 1. Treatment algorithm for primary care for patients with obesity. BMI, body mass index; CVD, cardiovascular disease.

months. ${ }^{1}$ In the United States (U.S.), adjuvant anti-obesity medications should be considered for patients with a body mass index (BMI) $\geq 30 \mathrm{~kg} / \mathrm{m}^{2}$ or for patients with BMI $\geq 27 \mathrm{~kg} / \mathrm{m}^{2}$ who have concomitant obesity-related diseases and for whom dietary and physical therapy has not been successful. ${ }^{2}$ However, the Asia-Pacific World Health Organization recommendations suggest that antiobesity drugs should be considered when BMI is $\geq 25 \mathrm{~kg} / \mathrm{m}^{2}$, or $\geq 23 \mathrm{~kg} / \mathrm{m}^{2}$ with associated comorbidities, in Asians. ${ }^{3}$ The Korean Society for the Study of Obesity recommends that pharmacotherapy for obesity should be considered when intensive lifestyle modifications fail to result in weight loss in obese patients with BMI $\geq 25 \mathrm{~kg} / \mathrm{m}^{2}$ (Fig. 1). ${ }^{4}$

Drugs have been used since the 1930s to conquer obesity, but due to serious side effects, most of the drugs used in the past are no longer in use. ${ }^{5}$ The agents involved include dinitrophenol, aminorex, the fenfluramine, phenylpropanolamine, and, most recently, rimonabant. Other drugs such as the amphetamine is severely restricted due to their potential for abuse. ${ }^{5}$ Rare examples are fenfluramine, dexfenfluramine, and fenfluramine-phentermine, which dominated the obesity market during the 1980s and 1990s as appetite suppressants. ${ }^{6}$ In 1997, the U.S. Food and Drug Administration (FDA) recalled the products. The drugs currently used to treat obesity in Korea are shown in Tables 1 and 2. Among them, the anti-obesity medications available for long-term treatment include orlistat, lorcaserin, a naltrexone/bupropion extended-release (ER), and liraglutide ( $3 \mathrm{mg}$ ). Phentermine/topiramate ER was approved by the U.S. FDA in 2012 for the treatment of obesity and is also currently available in Korea. In this paper, we provide an overview of the anti-obesity medications currently available for long-term treatment.

\section{PHARMACOTHERAPIES FOR OBESITY}

\section{Orlistat}

Orlistat is a drug for the treatment of obesity that was released in 2001 and has been proven to be safe. Orlistat causes weight loss by inhibiting lipase from the mucous membranes of the stomach and small intestine, preventing triglycerides from being broken down into fatty acids, and absorbed into the intestine. ${ }^{7,8}$ Taken at a therapeutic dose of $120 \mathrm{mg}$ tid (three times a day), orlistat inhibits the absorption of triglycerides in the intestine by about $30 \%$, resulting in more weight loss than fat-restricted meals and helping to improve various metabolic conditions. ${ }^{9}, 10$ After discontinuation of the drug, the fecal fat content usually returns to normal within $48-72$ hours. 
Table 1. Currently available anti-obesity medications: short-term use

\begin{tabular}{|c|c|c|c|c|c|}
\hline Orug & Action mechanism & Dosage & Adverse effect & Contraindication & DEA schedule \\
\hline nentermine & Sympathomimetic amine & $15-37.5 \mathrm{mg} \mathrm{qd}$ & Headache, elevated blood pressure, elevated & History of cardiovascular disease, hyperthyroidism, & IV \\
\hline Diethylpropion & Sympathomimetic amine & $25 \mathrm{mg}$ tid & heart rate, insomnia, dry mouth, constipation, & glaucoma, pregnancy, breastfeeding, history & IV \\
\hline Mazindol & Sympathomimetic amine & $1 \mathrm{mg}$ qd-tid & $\begin{array}{l}\text { anxiety, palpitations, dyspnea, angina } \\
\text { pectoris, syncope, severe hypertension }\end{array}$ & $\begin{array}{l}\text { of drug abuse, concomitant MAOI (within } \\
14 \text { days), agitated states, hypersensitivity }\end{array}$ & IV \\
\hline
\end{tabular}

Short-term medications are considered as a few weeks, usually up to 12 weeks.

DEA, Drug Enforcement Agency; qd, once a day; tid, three times a day; MAOI, monoamine oxidase inhibitor.

Table 2. Currently used anti-obesity medications: long-term use

\begin{tabular}{|c|c|c|c|c|c|}
\hline Drug & Action mechanism & Dosage & Adverse effect & Contraindication & DEA schedule \\
\hline Orlistat & $\begin{array}{l}\text { A reversible gastric and } \\
\text { pancreatic lipase inhibitor } \\
\text { that reduces the absorption } \\
\text { of dietary fat }\end{array}$ & 120 mg tid & $\begin{array}{l}\text { Steatorrhea, fecal urgency, incontinence, } \\
\text { flatulence, oily spotting, frequent bowel } \\
\text { movements, abdominal pain, headache, } \\
\text { severe liver injury, cholelithiasis, } \\
\text { malabsorption of fat-soluble vitamin }\end{array}$ & $\begin{array}{l}\text { Pregnancy, breastfeeding, chronic } \\
\text { malabsorption syndrome, cholestasis, } \\
\text { oxalate nephrolithiasis }\end{array}$ & None \\
\hline $\begin{array}{l}\text { Lorcaserin* } \\
\text { (Belviq) }\end{array}$ & 5-HT2C receptor agonist & $10 \mathrm{mg}$ qd or bid & $\begin{array}{l}\text { Headache, nausea, dizziness, fatigue, xerostomia, } \\
\text { dry eye, constipation, diarrhea, back pain, } \\
\text { nasopharyngitis, hyperprolactinemia, } \\
\text { uncontrolled mood disorder, cognitive } \\
\text { impairment, leukopenia }\end{array}$ & $\begin{array}{l}\text { Pregnancy, breastfeeding, serotonin } \\
\text { syndrome or neuroleptic malignant } \\
\text { syndrome }\end{array}$ & IV \\
\hline $\begin{array}{l}\text { Naltrexone/ } \\
\text { bupropion } \\
\text { (Contrave) }\end{array}$ & $\begin{array}{l}\text { Opioid antagonist/dopamine } \\
\text { and norepinephrine } \\
\text { reuptake inhibitor }\end{array}$ & 8/90 mg qd-2T bid & $\begin{array}{l}\text { Nausea, headache, insomnia, vomiting, } \\
\text { constipation, diarrhea, dizziness, anxiety, } \\
\text { xerostomia, cardiac arrhythmia, narrow-angle } \\
\text { glaucoma, uncontrolled migraine disorder, } \\
\text { generalized anxiety disorder, bipolar disorder, } \\
\text { seizures (bupropion lowers seizure threshold) }\end{array}$ & $\begin{array}{l}\text { Pregnancy, breastfeeding, uncontrolled } \\
\text { hypertension, seizure disorder, } \\
\text { anorexia nervosa, bulimia nervosa, } \\
\text { severe depression, drug or alcohol } \\
\text { withdrawal, concomitant MAOl } \\
\text { (within } 14 \text { days), chronic opioid use }\end{array}$ & None \\
\hline $\begin{array}{l}\text { Liraglutide } 3 \text { mg } \\
\text { (Saxenda) }\end{array}$ & GLP-1 analog & $0.6-3.0 \mathrm{mg} / \mathrm{day}$ & $\begin{array}{l}\text { Nausea, vomiting, diarrhea, constipation, } \\
\text { headache, dyspepsia, increased heart rate, } \\
\text { gastroparesis, pancreatitis, cholelithiasis, } \\
\text { suicidal ideation and behavior, injection site } \\
\text { reactions }\end{array}$ & $\begin{array}{l}\text { Pregnancy, breastfeeding, personal or } \\
\text { family history of medullary thyroid } \\
\text { cancer or MEN2, pancreatitis, acute } \\
\text { gallbladder disease }\end{array}$ & None \\
\hline $\begin{array}{l}\text { Phentermine/ } \\
\text { topiramate } \\
\text { (Osymia) }\end{array}$ & $\begin{array}{l}\text { Sympathomimetic amine/ } \\
\text { antiepileptic drug }\end{array}$ & 3.75/23-15/92 mg qd & $\begin{array}{l}\text { Headache, paresthesia, insomnia, decreased } \\
\text { bicarbonate, xerostomia, constipation, anxiety, } \\
\text { depression, cognitive impairment, dizziness, } \\
\text { nausea, dysgeusia, tachyarrhythmia, seizure } \\
\text { disorder, anxiety and panic attacks, } \\
\text { nephrolithiasis, hyperchloremic metabolic } \\
\text { acidosis, abuse potential }\end{array}$ & $\begin{array}{l}\text { Pregnancy, breastfeeding (topiramate } \\
\text { teratogenicity), hyperthyroidism, acute } \\
\text { angle-closure glaucoma, concomitant } \\
\text { MAOl use (within } 14 \text { days) }\end{array}$ & IV \\
\hline
\end{tabular}

* Lorcaserin withdrawn from market due to cancer risk.

DEA, Drug Enforcement Agency; tid, three times a day; HT, hydroxytryptamine; qd, once a day; bid, twice a day; MAOI, monoamine oxidase inhibitor; GLP-1, glucagon-like peptide-1; MEN2, multiple endocrine neoplasia type 2.

In a long-term study using orlistat (Xenical in the prevention of diabetes in obese subjects [XENDOS]), the weight loss rate was about 5\% higher than in the placebo group (11\% decrease vs. $6 \%$ decrease) (Table 3) and significant weight loss was maintained when compared to the placebo group four years later $(6.9 \%$ decrease vs. $4.1 \%$ decrease) (Fig. 2).${ }^{11}$ In addition, the progression from impaired glucose tolerance to T2DM decreased by $37 \%$ when the medication was taken for 4 years. ${ }^{11}$ In a meta-analysis of 30 placebo-controlled studies, orlistat reduced weight by $2.9 \mathrm{~kg}(95 \%$ confidence interval, $2.5-3.2 \mathrm{~kg}$ ) compared to the placebo. ${ }^{12} \mathrm{~Pa}$ tients receiving active drug treatment were significantly more likely to achieve $5 \%$ and $10 \%$ weight-loss thresholds. Orlistat reduced the incidence of T2DM, and decreased blood pressure (BP) and the concentrations of total cholesterol, and improved glycemic control in patients with $\mathrm{T} 2 \mathrm{DM} .^{13}$

Many studies have proven that orlistat has no systemic side effects and most side effects are limited to the gastrointestinal system. ${ }^{14}$ Over 2 years of treatment, more than $20 \%$ of the patients 


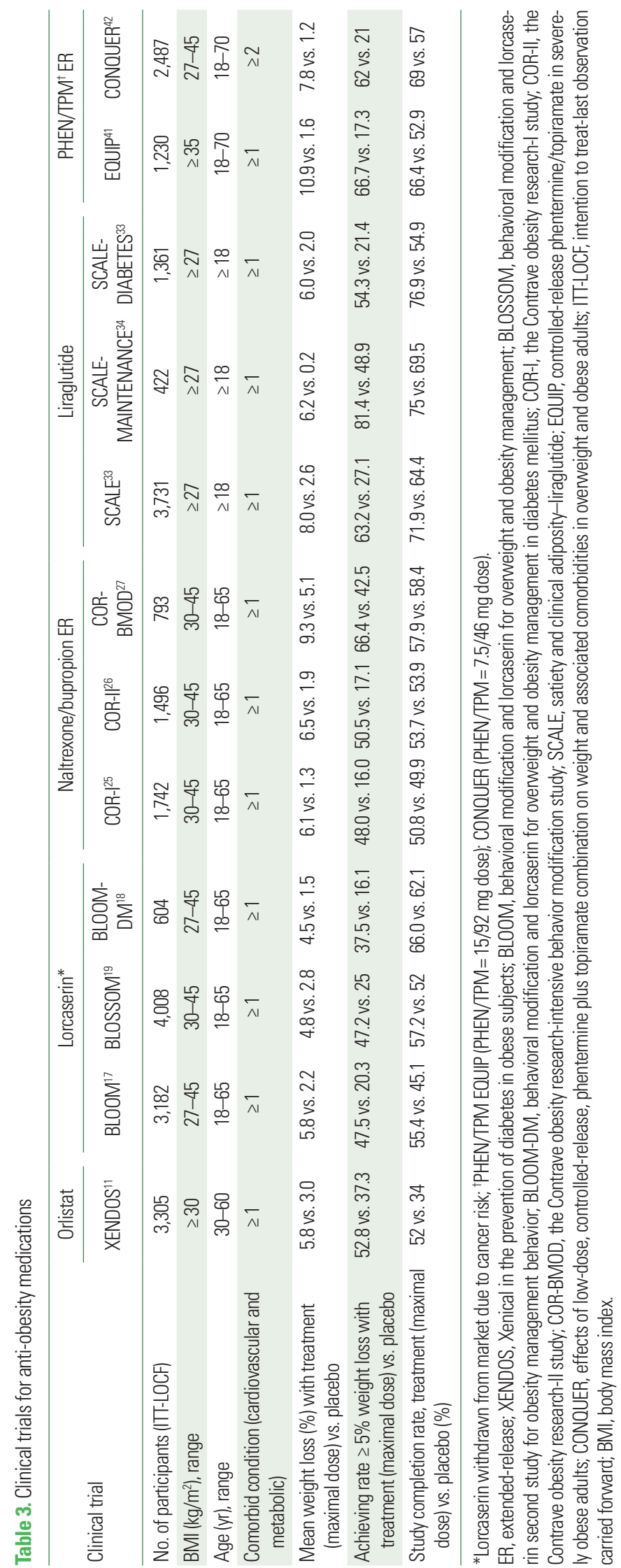

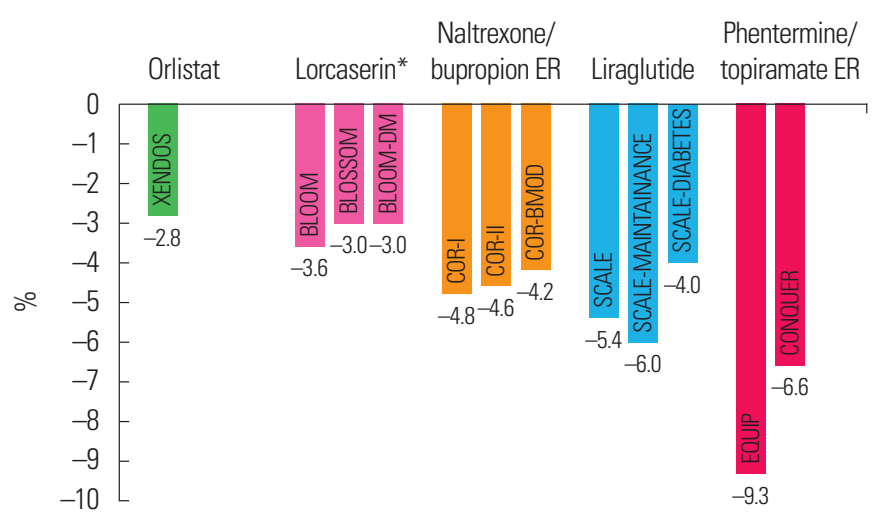

Figure 2. Placebo-subtracted mean weight loss (\%) in overweight/obese individuals in clinical trials. All data are placebo-subtracted, maximal dose, intention to treat, last observation carried forward, 1 year, unless otherwise indicated. *Lorcaserin withdrawn from market due to cancer risk. XENDOS, Xenical in the prevention of diabetes in obese subjects ${ }^{11}$; BLOOM, behavioral modification and lorcaserin for overweight and obesity management ${ }^{15}$; BLOSSOM, behavioral modification and lorcaserin second study for obesity managementbehavior ${ }^{16}$; BLOOM-DM, behavioral modification and lorcaserin for overweight and obesity management in diabetes mellitus ${ }^{17}$; COR-I, the Contrave obesity research-I study ${ }^{18}$; COR-II, the Contrave obesity research-II study ${ }^{19}$; COR-BMOD, the Contrave obesity research-intensive behavior modification study ${ }^{20}$; SCALE, satiety and clinical adiposity-liraglutide ${ }^{21}$; EQUIP, controlled-release phentermine/topiramate in severely obese adults $^{22}$; CONQUER, effects of low-dose, controlled-release, phentermine plus topiramate combination on weight and associated comorbidities in overweight and obese adults. ${ }^{23}$

complained of side effects that included stool incontinence, oily spotting, and fatty stools (Table 2). ${ }^{14}$

\section{Lorcaserin}

Lorcaserin is a highly selective 5-hydroxytryptamine (HT) 2C receptor agonist. ${ }^{24} \mathrm{By}$ activating the 5-HT2C receptor, lorcaserin decreases the energy intake through the pro-opiomelanocortin (POMC) system. Two other serotonergic agents (fenfluramine and dexfenfluramine) were removed from the market due to druginduced valvulopathy as the result of agonism at the 5-HT2B receptor subtype.

Three randomized, placebo-controlled, double-blind trials for the efficacy and safety of lorcaserin have been conducted. ${ }^{15-17}$ In the behavioral modification and lorcaserin for overweight and obesity management (BLOOM) study, participants in the lorcaserin group lost $5.8 \mathrm{~kg}$ and those in the placebo group lost $2.2 \mathrm{~kg}$ (Fig. 2). ${ }^{15}$ The behavioral modification and lorcaserin for overweight and obesity management in diabetes mellitus (BLOOM-DM) study, ${ }^{17}$ which consisted only of only 604 patients with T2DM, was a 1-year clini- 
cal study. A weight loss of more than 5\% was achieved by $37.5 \%$ of the patients treated with lorcaserin bid (twice a day), more than twice as much as the $16.1 \%$ in the placebo group (Table 3 ). The behavioral modification and lorcaserin second study for obesity management behavior (BLOSSOM) study was a large randomized, placebo-controlled, double-blind, parallel-arm trial of 4,008 obese or overweight patients to investigate weight loss. A total of 2,224 people (55.5\%) have completed the 1-year trial. The participants were randomized into three groups: lorcaserin $10 \mathrm{mg}$ bid, lorcaserin qd (once a day), and placebo. The percentage of patients who successfully achieved at least $5 \%$ weight loss was significantly higher in the lorcaserin group (bid, 47.2\%; qd, 40.2\%) than in the control group $(25 \% ; P<0.001)$ (Table 3$){ }^{16}$

In 2018 , the results of a study were released on the effects of lorcaserin and cardiovascular stability (cardiovascular and metabolic effects of lorcaserin in overweight and obese patients-thrombolysis in myocardial infarction 61 [CAMELLIA-TIMI 61] study) on 12,000 patients with atherosclerotic cardiovascular disease or obesity with multiple cardiovascular risk factors (BMI $>30 \mathrm{~kg} / \mathrm{m}^{2}$ ) or were overweight $\left(\mathrm{BMI}>27 \mathrm{~kg} / \mathrm{m}^{2}\right)$. During the 3.3-year follow-up period, the annual incidence of major adverse cardiovascular events was similar at $2.1 \%$ in the placebo group and $2.0 \%$ in the lorcaserin group. 25

The most common adverse events were headache, dizziness, and nausea. ${ }^{16,17}$ No adverse effects were found in the echocardiographic analysis of patients in the BLOOM-DM study. ${ }^{17}$ Although not observed in patients taking lorcaserin alone, the occurrence of serotonin syndrome or neuroleptic malignant syndrome, which may occur in conjunction with other serotonin agonists or in combination with anti-dopaminergic agents, should be monitored (Table 2).

In February 2020, the U.S. FDA asked the manufacturer of lorcaserin to voluntarily withdraw the weight-loss drug from the U.S. market because clinical trial showed an increased risk of cancer. ${ }^{26}$ In the randomized, double-blind, placebo-controlled clinical trial to evaluate the risk of cardiovascular problems (CAMELLIA-TIMI 61 study), more patients taking lorcaserin $(n=462 ; 7.7 \%)$ were diagnosed with cancer compared to those taking a placebo $(n=423$; 7.1\%). The trial was conducted in 12,000 patients over 5 years. A range of cancer types was reported, with several different types of cancers occurring more frequently in the lorcaserin group, includ- ing pancreatic, colorectal, and lung cancers. ${ }^{26}$ As a result, lorcaserin was voluntarily withdrawn from the Korean market.

\section{Naltrexone/bupropion ER}

Naltrexone/bupropion ER is a combination of drugs with two different mechanisms. Naltrexone is a drug used to treat addiction and alcoholism. Bupropion is an antidepressant and a drug used for the cessation of smoking. Bupropion is an antidepressant that inhibits the reabsorption of dopamine and norepinephrine, resulting in decreased food intake and weight loss through action in the hypothalamic POMC neurons. However, POMC is self-inhibited by endogenous opioids, which reduce the appetite suppression effect of bupropion. In combination with the opioid antagonist naltrexone, POMC activation by bupropion can enhance the appetite suppression effect by increasing POMC activation. ${ }^{27}$ Naltrexone has a different mechanism for weight reduction. The opioid receptor antagonist, naltrexone, is known to reduce hedonic feeding through m-opioid receptors (MORs). ${ }^{28}$ Endogenous opioids and MORs are important in the mechanism of appetite control and hedonic eating, consumption, and orosensory reward processes. ${ }^{29}$ In September 2014, the U.S. FDA approved the use of the drug for more than 6 months to treat obesity.

Four large-scale randomized, double-blind, controlled studies (Contrave obesity research (COR)-I, COR-II, the COR-intensive behavior modification study [COR-BMOD], and COR-Diabetes) compared a naltrexone-bupropion group to a control group for 1 year in obese or overweight patients (BMI $\geq 27 \mathrm{~kg} / \mathrm{m}^{2}$ ) with one or more metabolic comorbidities. ${ }^{18-20,30}$ The COR-I study showed a $6.1 \%$ weight loss in the naltrexone/bupropion $32 \mathrm{mg} / 360 \mathrm{mg}$ group and a $5.0 \%$ weight loss in the naltrexone/bupropion $16 \mathrm{mg} / 360 \mathrm{mg}$ group (Table 3). In contrast, the placebo group showed a 1.3\% weight loss. In addition, the rate of weight loss of more than $5 \%$ was significantly higher in the naltrexone/bupropion $32 \mathrm{mg} / 360 \mathrm{mg}$ group (48\%) and in the naltrexone/bupropion $16 \mathrm{mg} / 360 \mathrm{mg}$ group (39\%) than that of the placebo group (17\%). ${ }^{18}$ In the COR-II study, of 1,496 people with BMIs over $30 \mathrm{~kg} / \mathrm{m}^{2}$ or BMIs over $27 \mathrm{~kg} / \mathrm{m}^{2}$ and higher risk, the naltrexone/bupropion $32 \mathrm{mg} / 360 \mathrm{mg}$ group had a higher weight loss rate than the placebo group ( $-6.4 \%$ vs. $-1.2 \%$ ) (Fig. 2). In addition, the weight loss rate of $5 \%$ or more was significantly higher in the naltrexone/bupropion $32 \mathrm{mg} / 360 \mathrm{mg}$ 
group than in the placebo group ( $50.5 \%$ vs. $17.1 \%$ ) and the cardiovascular metabolic parameters were significantly improved (Table 3). ${ }^{19}$ All COR clinical studies have shown improved lipid concentrations and insulin resistance. ${ }^{18-20,30}$ Compared to the placebo group, the naltrexone-bupropion group not only reduced appetite and weight loss but also reduced food cravings, even when full. ${ }^{18}$ All antidepressants contain warnings of suicide. The fact that bupropion is used for depression and the cessation of smoking is of concern, but phase 3 studies of long-term weight control showed no suicide attempts. However, these tended to increase in patients younger than 24 years. In addition, seizures occurred in approximately 1 of 1,000 patients in studies using bupropion in combination with other drugs. Bupropion may lower seizure threshold and is contraindicated in patients with a history of seizures, which are more likely to occur in people with eating disorders, in alcohol withdrawal, and drug users. Bupropion should not be used in patients with uncontrolled hypertension, as it can increase pulse and BP within the first three months of treatment. In drug interactions, bupropion is metabolized by CYP2B6, which can increase the efficacy of bupropion in patients taking ticlopidine or clopidogrel. In addition, bupropion inhibits the CYP2D6 pathway, which may increase the efficacy of antidepressants, antipsychotics, beta-blockers, and type 1C arrhythmia medications (Table 2). ${ }^{31}$ Nausea and vomiting have been reported as major side effects of naltrexone, but in most cases, they are tolerated and tend to disappear over time. To prevent these side effects, the dose can be gradually increased. Like many of the available anti-obesity medications, naltrexone/bupropion ER increases heart rate. Because of the increase in heart rate (Table 2), the U.S. FDA required a cardiovascular outcome trial. However, a planned interim analysis was inappropriately released to the public in 2015, when the trial was still ongoing, so the study was terminated early. ${ }^{32}$ The non-inferiority of cardiovascular safety cannot be evaluated because of the early termination of the trial. Accordingly, the cardiovascular safety of naltrexone/bupropion ER remains uncertain and will require a new cardiovascular outcome trial.

\section{Liraglutide (3 mg)}

Liraglutide is a drug that acts on the glucagon-like peptide-1 (GLP-1) receptor and is already being used to treat T2DM. GLP-1 is a physiological modulator of appetite that increases satiety and reduces food intake. Liraglutide binds to GLP-1 receptors of the arcuate nucleus in the hypothalamus and directly activates POMC/ cocaine- and amphetamine-regulated transcript neurons. ${ }^{33}$ It promotes satiety and also inhibits neuropeptide $\mathrm{Y} /$ agouti-related protein neurons that cause fasting. ${ }^{33}$ As a result, liraglutide decreases food intake through appetite suppression, resulting in weight loss. Liraglutide (Victoza), developed for the treatment of T2DM, is available in $1.2 \mathrm{mg}$ or $1.8 \mathrm{mg}$ formulations. However, liraglutide in a $3 \mathrm{mg}$ formulation (Saxenda) was approved by the U.S. FDA in December 2014 for weight loss.

Four randomized, placebo-controlled, double-blind trials investigated the efficacy and safety of liraglutide $3 \mathrm{mg}$ for obesity management. ${ }^{21,3436}$ The participants were randomized to receive liraglutide (3.0 mg sc daily) or placebo for initial weight loss in the satiety and clinical adiposity-liraglutide (SCALE; patients without diabetes) and SCALE Diabetes (patients with diabetes) trials or weight maintenance after initial weight loss (SCALE Maintenance) (Table 3). The SCALE Obesity and Prediabetes study, published in 2015, was a 56-week study in 3,731 patients with no T2DM, BMIs $\geq 30 \mathrm{~kg} / \mathrm{m}^{2}$ or $27 \mathrm{~kg} / \mathrm{m}^{2}$, and hypertension or dyslipidemia. In the liraglutide group, an average weight loss of $8.4 \mathrm{~kg}$ was observed. Weight loss of more than $10 \%$ was significantly superior in the liraglutide group at $33.1 \%$ compared to the placebo group at $10.6 \%$ (Fig. 2). ${ }^{34}$

The liraglutide effect and action in diabetes: evaluation of cardiovascular outcome results (LEADER) trial assessed the long-term effects of liraglutide $(1.8 \mathrm{mg})$ on cardiovascular outcomes and other clinically important events in diabetic patients. ${ }^{37}$ The LEADER trial was not designed for obesity management. A total of 9,340 diabetic patients were randomly assigned to the liraglutide group or the placebo group. During the mean follow-up period of 3.8 years, cardiovascular disease, myocardial infarctions, and cerebral infarction deaths were significantly less in the liraglutide group ( $13 \%$ vs. $14.9 \%)$, and cardiovascular mortality was significantly less in the liraglutide group ( $4.7 \%$ vs. $6.0 \%){ }^{37}$ The main side effect was nausea, which was reported to be the highest after four weeks, the time when the first $3.0 \mathrm{mg}$ dose was administered after the $0.6 \mathrm{mg}$ dose, and decreased gradually thereafter. Other side effects included diarrhea, constipation, decreased appetite, and the risk of pancreatitis. There is a concern that the use of incretin preparations is associated with pancreatitis. However, it is difficult to determine the causal re- 
lationship between liraglutide administration and pancreatitis. ${ }^{38}$ Studies of liraglutide in rodents have resulted in C-cell cancer of the thyroid gland ${ }^{39}$ because liraglutide stimulates the GLP-1 receptor on thyroid C cells. For this reason, in many phase III clinical trials, the serum calcitonin concentrations of the participants were measured using assays with high sensitivity and specificity for C-cell pathology. When the participants were administered up to $3.0 \mathrm{mg}$ of liraglutide daily for up to 2 years, the researchers concluded that there was no evidence that liraglutide stimulates calcitonin secretion in human $\mathrm{C}$ cells. ${ }^{40}$ However, it should not be used in patients with a history of or suspected of having a high risk for medullary thyroid cancer or multiple endocrine adenomas (Table 2).

\section{Phentermine/topiramate ER combination}

Phentermine/topiramate ER is a combination of a traditional short-term appetite suppressant (phentermine) and a long-acting neurotherapeutic drug (topiramate). Phentermine/topiramate ER was approved by the U.S. FDA in 2012 and also is currently available in Korea. Phentermine is a drug that suppresses the appetite by increasing norepinephrine secretion in the hypothalamus and is approved for the short-term treatment of obesity. Topiramate is a drug used to treat epilepsy and prevent migraines. Although clinical studies have shown that topiramate itself has a weight loss effect, it is not clear which drug mechanism induces weight loss. ${ }^{41}$ Topiramate is thought to cause weight loss by increasing energy consumption, reduced calorie intake, and taste disorders. Topiramate has many neurological side effects when administered in sufficient doses to induce weight loss. Similarly, phentermine also increases weight loss, but with more side effects. This has led to the development of a combination therapy that combines phentermine and topiramate at low doses with low side effects.

The EQUIP study was undertaken to evaluate the safety and efficacy of phentermine and topiramate ER for weight loss and metabolic improvements. ${ }^{41}$ Men and women with class II and III obesity (BMI $\geq 35 \mathrm{~kg} / \mathrm{m}^{2}$ ) were randomized to placebo, phentermine/ topiramate ER 3.75/23 mg or phentermine/topiramate ER 15/92 $\mathrm{mg}$ added to a reduced-energy diet. The patients in the placebo, $3.75 / 23 \mathrm{mg}$, and $15 / 92 \mathrm{mg}$ groups lost $1.6 \%, 5.1 \%$, and $10.9 \%$ of their baseline body weight, respectively, at 56 weeks (Fig. 2). In the study, $17.3 \%$ of the placebo patients, $44.9 \%$ of the $3.75 / 23 \mathrm{mg}$ pa- tients, and $66.7 \%$ of the $15 / 92 \mathrm{mg}$ patients lost at least $5 \%$ of their baseline body weight at 56 weeks (Table 3). The phentermine/ topiramate ER $15 / 92 \mathrm{mg}$ group had significantly greater changes in systolic and diastolic BP, fasting glucose, and lipid profiles compared to the placebo group. ${ }^{22}$

The effects of low-dose, controlled-release, phentermine plus topiramate combination on weight and associated comorbidities in overweight and obese adults (CONQUER) study ${ }^{23}$ included the largest number of patients and was extended to the two-year sustained weight loss and metabolic benefits with controlled-release phentermine/topiramate in obese and overweight adults (SEQUEL) study ${ }^{42}$ This was a large-scale phase III clinical study that involved 2,487 people (aged 18-70 years) of all ages at 93 research centers in the United States. All patients had a BMI of $27-45 \mathrm{~kg} / \mathrm{m}^{2}$ and had two or more metabolic comorbidities (hypertension, hyperlipidemia, T2DM or pre-stage T2DM, and obesity). They were randomized to the placebo group at a 2:1:2 ratio and given phentermine/topiramate 7.5/46.0 mg or phentermine/topiramate 15.0/ $92.0 \mathrm{mg}$, once daily. Weight loss at the end of the 56-week study was $-1.4 \mathrm{~kg},-8.1 \mathrm{~kg}$, and $-10.2 \mathrm{~kg}$ in the placebo, $7.5 / 46.0 \mathrm{mg}$, and 15.0/92.0 mg groups, respectively (Fig. 2). The number of patients that achieved a weight loss of 5\% or more was 204 (21\%), 303 (62\%), and 687 (70\%) patients in the placebo, 7.5/46.0 $\mathrm{mg}$, and 15.0/92.0 mg groups, respectively, demonstrating very effective results (Table 3). The most common side effect was dry mouth with other side effects, i.e., paresthesia, constipation, insomnia, dizziness, and dysgeusia.

The SEQUEL study was designed to extend the CONQUER study to investigate the effects of treatment for a total of 108 weeks. Of the 676 subjects, those who completed this period had a high completion rate of $84 \%$ and there were no significant differences among the three groups. Patients in the phentermine/topiramate ER group showed improvement in cardiovascular variables, i.e., BP, triglyceride, high-density lipoprotein-cholesterol, low-density lipoprotein-cholesterol, and metabolic syndrome variables, e.g., glycosylated hemoglobin. The incidence of T2DM was reduced compared to the placebo group. A reduction in adverse events was reported at 56-108 weeks, compared to weeks $0-56$ and 56-108.

Phentermine/topiramate ER is the most effective anti-obesity drug available. ${ }^{43}$ Side effects related to depression and cognition 
were not a major problem in recent clinical studies. Phentermine can activate the sympathetic nervous system and is not recommended for patients with a history of cardiovascular disease. Topiramate must be administered with caution because of its relationship to metabolic acidosis, especially in patients with kidney stones. In rare cases, acute glaucoma has been reported as an idiopathic reaction, so it is necessary to stop the drug immediately. The main concern is the risk of oral clefts in infants that may result from exposure to topiramate in utero. ${ }^{44}$ Women of childbearing age taking the drug are urged to use effective contraception (Table 2).

\section{INDIVIDUALIZED TREATMENT: WHICH DRUGS FOR WHICH PATIENT?}

\section{Type 2 diabetes mellitus}

Currently available anti-obesity medications can be used according to the characteristics of each patient if there is no contraindication in diabetic patients. ${ }^{45}$ However, sympathomimetic agents should be avoided in diabetic patients with cardiovascular disease or uncontrolled hypertension. Liraglutide has been developed as a treatment for T2DM, so it is excellent for improving hyperglycemia in obese patients with T2DM. If obese patients with T2DM are willing to receive a subcutaneous injection, liraglutide may be a priority for weight control.

\section{Chronic kidney disease}

Most anti-obesity medications should not be used in patients with end-stage renal disease. However, orlistat and liraglutide can be used carefully in some patients. Naltrexone/bupropion ER or phentermine/topiramate ER is not recommended in patients with severe renal impairment $(<30 \mathrm{~mL} / \mathrm{min})$. Orlistat is not recommended due to the risk of oxalate nephropathy. Liraglutide (3 mg) has to be discontinued if dehydration occurs due to vomiting or diarrhea. $^{45}$

\section{Hepatic impairment}

All anti-obesity medications should not be used in patients with severe hepatic impairment (Child-Pugh score >9). However, some anti-obesity medications can be used for patients with moderate hepatic impairment after dose adjustment. For patients with mod- erate hepatic impairment, a one tablet dose of naltrexone/bupropion ER ( $8 \mathrm{mg} / 90 \mathrm{mg})$ is recommended, and a dose of $7.5 \mathrm{mg} / 46 \mathrm{mg}$ phentermine/topiramate ER is recommended daily. ${ }^{45}$

\section{Hypertension}

Orlistat, phentermine/topiramate ER, and liraglutide can be used in patients with hypertension. However, liraglutide ( $3 \mathrm{mg}$ ) and phentermine/topiramate ER can increase heart rate, so heart rate should be monitored as a precaution in patients receiving these medications. Naltrexone/bupropion ER should be avoided in patients with hypertension and this medication is contraindicated in patients with uncontrolled hypertension. ${ }^{45}$

\section{Cardiovascular disease and cardiac arrhythmia}

In patients with established atherosclerotic cardiovascular disease, orlistat, and liraglutide $(3 \mathrm{mg})$ are recommended. Phentermine/topiramate ER and naltrexone/bupropion ER can be used with the careful monitoring of heart rate and BP. Orlistat is a very safe anti-obesity medication in patients with a history of cardiac arrhythmia. Naltrexone/bupropion ER, liraglutide, and phentermine/topiramate ER are not contraindicated but have to be used carefully including monitoring of heart rate and cardiac rhythm. ${ }^{45}$

\section{Depression and anxiety}

Orlistat, liraglutide ( $3 \mathrm{mg})$, and phentermine/topiramate ER (low dose) may be used in patients with depression. Naltrexone/ bupropion ER should be used carefully in patients with depression. In particular, as with other antidepressants, naltrexone/bupropion ER may increase the risk of suicide. However, these medications should be avoided if patients are taking other antidepressants. In patients with anxiety disorders, phentermine/topiramate ER is not contraindicated, but a high dose of phentermine/topiramate ER should be used with caution. ${ }^{45}$

\section{Seizure disorder}

Phentermine/topiramate ER, liraglutide, and orlistat can be used in patients with a history of or at risk of seizure disorder. Naltrexone/bupropion ER should be avoided in these patients. ${ }^{45}$ 


\section{CONCLUSION}

Obesity is a serious and growing health problem around the world. In clinical care, a focus on lifestyle changes in obese patients is the most practical treatment strategy. There are now several antiobesity medications, however, these drugs are not widely prescribed. The reasons might be the result of adverse events associated with older drugs and perhaps because of the unwillingness of many physicians. We reviewed the anti-obesity medications currently available for long-term treatment. The U.S. FDA asked the manufacturer to voluntary withdraw the weight-loss drug lorcaserin from the market due to its association with an increased risk of cancer. Orlistat, liraglutide ( $3 \mathrm{mg})$, naltrexone/bupropion ER, and phentermine/topiramate ER are well-tolerated and safe. The common side effects for these drugs are well known and can be prevented and controlled by appropriate dose. These drugs have been reported to be helpful in the management of metabolic diseases, as well as weight loss, but should be used in consideration of comorbid diseases, drug interactions, contraindications, and the risk of side effects. Further research is needed on the long-term effects, safety, and combination of anti-obesity medications.

\section{CONFLICTS OF INTEREST}

The authors declare no conflict of interest.

\section{ACKNOWLEDGMENTS}

This work was supported by the Korean Society for the Study of Obesity.

\section{AUTHOR CONTRIBUTIONS}

Study concept and design: BYK and CHK; acquisition of data: SMK, JHK (Jee-Hyun Kang), KKK, and BK; analysis and interpretation of data: SJK, YHK, JHK (Jung-Hwan Kim), GEN, JYP, JWS, HJS, and TJO; drafting of the manuscript: BYK and CHK; critical revision of the manuscript: BYK, SMK, JHK (Jee-Hyun Kang), KKK, BK, SJK, YHK, JHK (Jung-Hwan Kim), JHK (Jae Hyun Kim), GEN, JYP, JWS, HJS, TJO, HL, EJJ, SC, YHH, and
CHK; administrative, technical, or material support: HL, EJJ, SC, and $\mathrm{YHH}$; and study supervision: $\mathrm{CHK}$.

\section{REFERENCES}

1. Curioni CC, Lourenço PM. Long-term weight loss after diet and exercise: a systematic review. Int J Obes (Lond) 2005;29: 1168-74.

2. Apovian CM, Aronne LJ, Bessesen DH, McDonnell ME, Mu$\operatorname{rad} \mathrm{MH}$, Pagotto U, et al. Pharmacological management of obesity: an endocrine Society clinical practice guideline. J Clin Endocrinol Metab 2015;100:342-62.

3. World Health Organization, Regional Office for the Western Pacific. The Asia-Pacific perspective: redefining obesity and its treatment. Sydney: Health Communications Australia; 2000.

4. Seo MH, Lee WY, Kim SS, Kang JH, Kang JH, Kim KK, et al. 2018 Korean Society for the Study of Obesity guideline for the management of obesity in Korea. J Obes Metab Syndr 2019;28:40-5.

5. Ioannides-Demos LL, Piccenna L, McNeil JJ. Pharmacotherapies for obesity: past, current, and future therapies. J Obes 2011;2011:179674.

6. Jick H, Vasilakis C, Weinrauch LA, Meier CR, Jick SS, Derby LE. A population-based study of appetite-suppressant drugs and the risk of cardiac-valve regurgitation. N Engl J Med 1998; 339:719-24.

7. Vetter ML, Faulconbridge LF, Webb VL, Wadden TA. Behavioral and pharmacologic therapies for obesity. Nat Rev Endocrinol 2010;6:578-88.

8. Bray GA, Ryan DH. Medical therapy for the patient with obesity. Circulation 2012;125:1695-703.

9. McNeely W, Benfield P. Orlistat. Drugs 1998;56:241-9.

10. Drew BS, Dixon AF, Dixon JB. Obesity management: update on orlistat. Vasc Health Risk Manag 2007;3:817-21.

11. Torgerson JS, Hauptman J, Boldrin MN, Sjöström L. XENical in the prevention of diabetes in obese subjects (XENDOS) study: a randomized study of orlistat as an adjunct to lifestyle changes for the prevention of type 2 diabetes in obese patients. Diabetes Care 2004;27:155-61.

12. Rucker D, Padwal R, Li SK, Curioni C, Lau DC. Long term 
pharmacotherapy for obesity and overweight: updated metaanalysis. BMJ (Clinical research ed) 2007;335:1194-9.

13. Montan PD, Sourlas A, Olivero J, Silverio D, Guzman E, Kosmas CE. Pharmacologic therapy of obesity: mechanisms of action and cardiometabolic effects. Ann Transl Med 2019;7: 393.

14. Hauptman J, Lucas C, Boldrin MN, Collins H, Segal KR. Orlistat in the long-term treatment of obesity in primary care settings. Arch Fam Med 2000;9:160-7.

15. Smith SR, Weissman NJ, Anderson CM, Sanchez M, Chuang E, Stubbe S, et al. Multicenter, placebo-controlled trial of lorcaserin for weight management. N Engl J Med 2010;363:245-56.

16. Fidler MC, Sanchez M, Raether B, Weissman NJ, Smith SR, Shanahan WR, et al. A one-year randomized trial of lorcaserin for weight loss in obese and overweight adults: the BLOSSOM trial. J Clin Endocrinol Metab 2011;96:3067-77.

17. O'Neil PM, Smith SR, Weissman NJ, Fidler MC, Sanchez M, Zhang J, et al. Randomized placebo-controlled clinical trial of lorcaserin for weight loss in type 2 diabetes mellitus: the BLOOMDM study. Obesity (Silver Spring) 2012;20:1426-36.

18. Greenway FL, Fujioka K, Plodkowski RA, Mudaliar S, Guttadauria M, Erickson J, et al. Effect of naltrexone plus bupropion on weight loss in overweight and obese adults (COR-I): a multicentre, randomised, double-blind, placebo-controlled, phase 3 trial. Lancet 2010;376:595-605.

19. Apovian CM, Aronne L, Rubino D, Still C, Wyatt H, Burns C, et al. A randomized, phase 3 trial of naltrexone SR/bupropion SR on weight and obesity-related risk factors (COR-II). Obesity (Silver Spring) 2013;21:935-43.

20. Wadden TA, Foreyt JP, Foster GD, Hill JO, Klein S, O’Neil $\mathrm{PM}$, et al. Weight loss with naltrexone SR/bupropion SR combination therapy as an adjunct to behavior modification: the COR-BMOD trial. Obesity (Silver Spring) 2011;19:110-20.

21.Davies MJ, Bergenstal R, Bode B, Kushner RF, Lewin A, Skjøth TV, et al. Efficacy of liraglutide for weight loss among patients with type 2 diabetes: the SCALE diabetes randomized clinical trial. JAMA 2015;314:687-99.

22. Allison DB, Gadde KM, Garvey WT, Peterson CA, Schwiers ML, Najarian T, et al. Controlled-release phentermine/topiramate in severely obese adults: a randomized controlled trial
(EQUIP). Obesity (Silver Spring) 2012;20:330-42.

23. Gadde KM, Allison DB, Ryan DH, Peterson CA, Troupin B, Schwiers ML, et al. Effects of low-dose, controlled-release, phentermine plus topiramate combination on weight and associated comorbidities in overweight and obese adults (CONQUER): a randomised, placebo-controlled, phase 3 trial. Lancet 2011; 377:1341-52.

24. Ross EM, Roberts WC. The carcinoid syndrome: comparison of 21 necropsy subjects with carcinoid heart disease to 15 necropsy subjects without carcinoid heart disease. Am J Med 1985; 79:339-54.

25. Bohula EA, Wiviott SD, McGuire DK, Inzucchi SE, Kuder J, Im K, et al. Cardiovascular safety of lorcaserin in overweight or obese patients. N Engl J Med 2018;379:1107-17.

26. U.S. Food and Drug Administration. FDA requests the withdrawal of the weight-loss drug Belviq, Belviq XR (lorcaserin) from the market [Internet]. Silver Spring, MD: U.S. Food and Drug Administration; 2020 [cited 2020 Apr 5]. Available from: https://www.fda.gov/drugs/drug-safety-and-availability/fdarequests-withdrawal-weight-loss-drug-belviq-belviq-xr-lorcaserin-market

27. Caixàs A, Albert L, Capel I, Rigla M. Naltrexone sustained-release/bupropion sustained-release for the management of obesity: review of the data to date. Drug Des Devel Ther 2014;8: 1419-27.

28. Holtzman SG. Suppression of appetitive behavior in the rat by naloxone: lack of effect of prior morphine dependence. Life Sci 1979;24:219-26.

29. Nathan PJ, Bullmore ET. From taste hedonics to motivational drive: central $\mu$-opioid receptors and binge-eating behaviour. Int J Neuropsychopharmacol 2009;12:995-1008.

30. Smith SR, Fujioka K, Gupta AK, Billes SK, Burns C, Kim D, et al. Combination therapy with naltrexone and bupropion for obesity reduces total and visceral adiposity. Diabetes Obes Metab 2013;15:863-6.

31. Fujioka K. Safety and tolerability of medications approved for chronic weight management. Obesity (Silver Spring) 2015;23 Suppl 1:S7-11.

32. Nissen SE, Wolski KE, Prcela L, Wadden T, Buse JB, Bakris G, et al. Effect of naltrexone-bupropion on major adverse cardio- 
vascular events in overweight and obese patients with cardiovascular risk factors: a randomized clinical trial. JAMA 2016; 315:990-1004.

33. Secher A, Jelsing J, Baquero AF, Hecksher-Sørensen J, Cowley MA, Dalbøge LS, et al. The arcuate nucleus mediates GLP-1 receptor agonist liraglutide-dependent weight loss. J Clin Invest 2014;124:4473-88.

34. Pi-Sunyer X, Astrup A, Fujioka K, Greenway F, Halpern A, Krempf M, et al. A randomized, controlled trial of $3.0 \mathrm{mg}$ of liraglutide in weight management. N Engl J Med 2015;373: 11-22.

35. Wadden TA, Hollander P, Klein S, Niswender K, Woo V, Hale PM, et al. Weight maintenance and additional weight loss with liraglutide after low-calorie-diet-induced weight loss: the SCALE Maintenance randomized study. Int J Obes (Lond) 2013;37: 1443-51.

36. Blackman A, Foster GD, Zammit G, Rosenberg R, Aronne L, Wadden T, et al. Effect of liraglutide $3.0 \mathrm{mg}$ in individuals with obesity and moderate or severe obstructive sleep apnea: the SCALE Sleep Apnea randomized clinical trial. Int J Obes (Lond) 2016;40:1310-9.

37. Marso SP, Daniels GH, Brown-Frandsen K, Kristensen P, Mann JF, Nauck MA, et al. Liraglutide and cardiovascular outcomes in type 2 diabetes. N Engl J Med 2016;375:311-22.

38. Funch D, Gydesen H, Tornøe K, Major-Pedersen A, Chan KA. A prospective, claims-based assessment of the risk of pancreatitis and pancreatic cancer with liraglutide compared to other antidiabetic drugs. Diabetes Obes Metab 2014;16:273-5.

39. Martín-Lacave I, Bernab R, Sampedro C, Conde E, FernándezSantos JM, San Martín MV, et al. Correlation between gender and spontaneous C-cell tumors in the thyroid gland of the Wistar rat. Cell Tissue Res 1999;297:451-7.

40. Hegedüs L, Moses AC, Zdravkovic M, Le Thi T, Daniels GH. GLP-1 and calcitonin concentration in humans: lack of evidence of calcitonin release from sequential screening in over 5000 subjects with type 2 diabetes or nondiabetic obese subjects treated with the human GLP-1 analog, liraglutide. J Clin Endocrinol Metab 2011;96:853-60.

41. Bray GA, Hollander P, Klein S, Kushner R, Levy B, Fitchet M, et al. A 6-month randomized, placebo-controlled, dose-ranging trial of topiramate for weight loss in obesity. Obes Res 2003; 11:722-33.

42. Garvey WT, Ryan DH, Look M, Gadde KM, Allison DB, Peterson CA, et al. Two-year sustained weight loss and metabolic benefits with controlled-release phentermine/topiramate in obese and overweight adults (SEQUEL): a randomized, placebo-controlled, phase 3 extension study. Am J Clin Nutr 2012; 95:297-308.

43. Khera R, Murad MH, Chandar AK, Dulai PS, Wang Z, Prokop LJ, et al. Association of pharmacological treatments for obesity with weight loss and adverse events: a systematic review and meta-analysis. JAMA 2016;315:2424-34.

44. Yanovski SZ, Yanovski JA. Long-term drug treatment for obesity: a systematic and clinical review. JAMA 2014;311:74-86.

45. Garvey WT, Mechanick JI, Brett EM, Garber AJ, Hurley DL, Jastreboff AM, et al. American Association of Clinical Endocrinologists and American College of Endocrinology comprehensive clinical practice guidelines for medical care of patients with obesity. Endocr Pract 2016;22 Suppl 3:1-203. 